\title{
ナノインプリント技術の進展
}

\author{
廣島 洋*
}

\section{Progress of Nanoimprint Technology}

\author{
Hiroshi HIROSHIMA*
}

\begin{abstract}
* 国立研究開発法人産業技術総合研究所集積マイクロシステム研究センター（† 305-8564 茨城県つくば市並木 1-2-1）
* Research Center for Ubiquitous MEMS and Micro Engineering (UMEMSME), National Institute of Advanced Industrial Science and Technology (AIST) (1-2-1 Namiki, Tsukuba, Ibaraki 305-8564)
\end{abstract}

\section{1. はじめに}

ナノインプリントとは, しばしばNIL と呼ばれるが, こ れはナノインプリントが Stephen Chou 教授（現在, プリン ストン大）が 1995 年にミネソタ大でナノインプリントを開

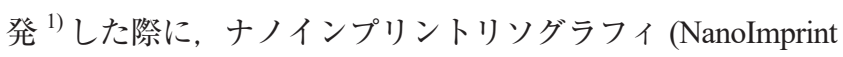
lithography) として発表しためである。このときのナノイン プリントは熱サイクルを利用する熱ナノインプリントであ る。また, 光ナノインプリントでは, フィリップス研究所 の Haisma 博士らによる Mold-assisted nanolithography ${ }^{2)}$ や, Texas 大学の Willson 教授らの S-FIL (Step and Flash Imprint Lithography) $)^{3)}$ を起源とする Molecular Imprints 社が半導体 およびパターンドメディア作製用リソグラフィとして開 発を進め ${ }^{4)}$ (その後 S-FIL は J-FIL (Jet and Flash Imprint Lithography) と名称変更), さらに, その半導体応用部門が Canonにより買収され, Canon Nanotechnologies となり, 現 在, 東芝メモリにより光ナノインプリントリソグラフィに よる半導体製造がはじまろうとしている。また, ナノイン プリントは半導体以外にも, モスアイ構造の反射防止フィ ルムや GaN 用の PSS (Patterned Sapphire Substrate) の製造に 用いられている。ここでは, ナノインプリントリソグラ フィ, 特に, 光ナノインプリントリソグラフィに注目し技 術の進展を解説する。

\section{2. ナノインプリントによる微細パターニング}

光リソグラフィにおいて, 1995 年は $\mathrm{KrF}$ スキャナーが開 発され解像度が $250 \mathrm{~nm}$ 程度を達成した年である。この時 にナノインプリントが発表された。タイトルは “Imprint of sub-25 nm vias and trenches in polymers”1) であり, 最先端の 光リソグラフィのまさに一桁上を行く驚嘆すべき技術であ る。この時点でナノインプリントはリソグラフィとして使 用され, $25 \mathrm{~nm}$ 径の微細な $\mathrm{Ti} / \mathrm{Au}$ ドットがシリコン基板に 作製されている。ナノインプリントリソグラフィの用語 は, 翌 1996 年に発表された論文 ${ }^{5)}$ のタイトル “Nanoimprint
Lithography”により示され，その概念が定着した。1997年 には “Sub-10 nm imprint lithography and application”にて 40 $\mathrm{nm}$ ピッチで $10 \mathrm{~nm}$ 径の $\mathrm{Ti} / \mathrm{Au}$ のリフトオフによる作製を 行い, $6 \mathrm{~nm}$ 径の微細なドットの作製にも成功している ${ }^{6}$ 。 この技術は, MIT Technology Review の 2003 年 2 月号にて 世界を変える 10 の新技術の一つとして紹介されている。リ ソグラフィでないナノインプリントに限れば, サファイア の $0.3 \mathrm{~nm}$ の原子ステップの転写を PMMA に行ったという 例 $^{7)}$ もある。これは, いずれも熱ナノインプリントの場 合であるが, 光ナノインプリントにおいても同様に微細パ ターンの作製が行われ，ハーフピッチ $20 \mathrm{~nm}$ の SRAM (Static random access memory)への適用を目指した金属配線パ夕ー ンの形成 ${ }^{8)}$ や $1 \mathrm{~nm}$ のパターン形成 ${ }^{9)}$ やシリコンの原子ス テップの転写例がある ${ }^{10)}$ 。このように, ナノインプリント はモールドさえあればナノメータ寸法のパターン形成が可 能であることが数多く実証されている。

\section{3. 光ナノインプリントリソグラフィ}

\section{1 熱ナノインプリントと光ナノインプリント}

熱ナノインプリントリソグラフィでは $10 \mathrm{~nm}$ 級のパター ン形成が可能であるものの, リソグラフィを指向した場合 にパターン形成時に温度が変化するためパターン配置精度 の点で課題を有していた。この点で光ナノインプリントは 温度の変化を伴わず，光を照射することで樹脂を硬化させ るのでパターン配置精度の点で有利である。また, 温度変 化には一般に時間がかかるためスループットの点でも光ナ ノインプリントに分がある。また，シリコンウエハなどに 対して, ステップアンドリピートによりパターン形成する 場合も光ナノインプリントの方が容易である。このような 光ナノインプリントを使用したナノインプリントリソグラ フィについて進展を述べる。

\section{2 モールドの離型剂処理}

ナノインプリントリソグラフィは最終的にはパーティク ルとの闘いになるが, その問題が無かったとしても解決す 
べきさまざまの問題がある。離型の問題, 残膜の問題, 重 ね合わせの問題などがある。ナノインプリントでは平らな シリコン基板に対して凹凸のあるモールドにより樹脂を成 型する。つまり, 基板側よりもモールド側の表面積が大き く, そもそも離型が難しい。このため, 一般的にはモール ド側に離型剤による処理を行う。離型剂はフッ素系のシラ ンカップリング剂 ${ }^{11}$ を用いる場合が多い, フッ素が多いほ ど離型性は一般的には良くなるが，分子サイズも大きくな りナノ寸法での成型ではパターン寸法の偏差になる。フッ 化アルキル基の長さと離型性の調查からフッ素が 13 個の FAS-13 (1,1,2,2-tetrahydro-perfluorooctyltrimethoxysilane) が分 子サイズも小さく離型性も高いことが示されている。ペン タフルオロプロパン (1,1,1,3,3,-pentafluoropropane; PFP) の環 境下でこの離型剂を使用したところ, 光硬化樹脂との相性 にもよるが 20,000 回以上のインプリントに耐えることがで きると実証されている (図 1) ${ }^{12)}$ 。

\section{3 バブル欠陥の抑止}

ここで雲囲気として用いた PFP はバブル欠陥抑止のため に使用されている ${ }^{13)}$ 。バブル欠陥は大気中で低加圧プロセ スの光ナノインプリントに特有の現象であり, 捕獲された 大気により樹脂の未充填部分が発生する現象である。この 現象は熱ナノインプリントでは問題となっておらず，ま た，光ナノインプリントにおいてもリソグラフィ的ではな

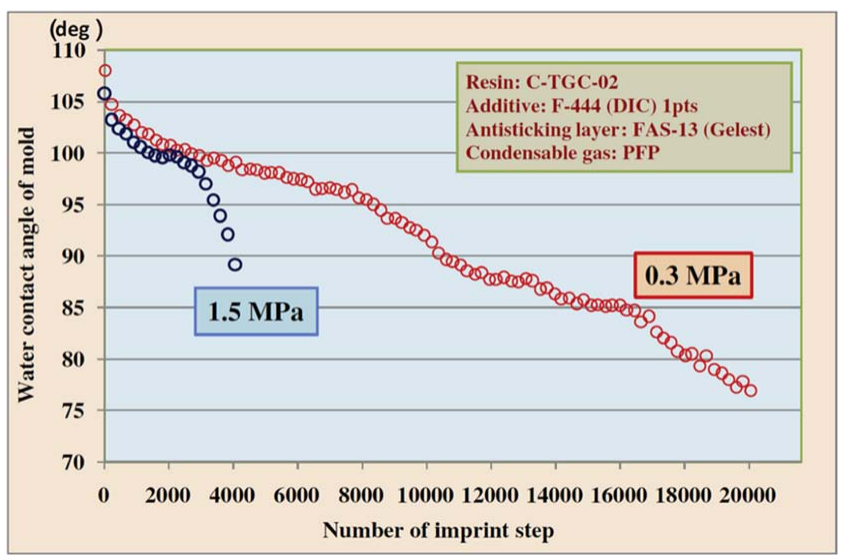

図 1. 離型剤FAS-13 処理モールド表面のインプリント回 数と水の接触角の関係 ${ }^{12)}$

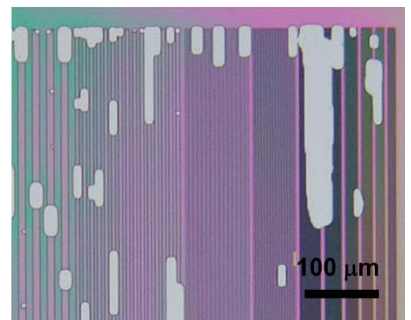

(a) 大気中プロセス

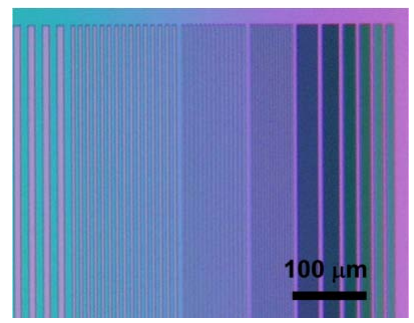

(b) PFP 中プロセス
図 2. 大気中と PFP 中での光ナノインプリントにおけるバ ブル欠陥 ${ }^{13)}$
い残膜が十分に厚い条件では，捕獲気体の樹脂への溶解や 樹脂流動による捕獲気体の排出 ${ }^{14)} に よ り$ 問題とならない場 合がある。しかし，ナノインプリントリソグラフィを指向 した低残膜厚条件のプロセスでは図 2(a) のようなバブル欠 陥が発生する ${ }^{13)}$ 。インプリント環境を真空にして，そもそ もガスの捕獲が起こらない様にする方法のほかに，ポーラ スな材料でモールドを作製 ${ }^{15)}$ することや石英を透過する $\mathrm{He}$ 環境を利用 ${ }^{16)}$ するなどの捕獲されたガスをモールド透 過させる手法がある。PFP はこれらとは異なり，捕獲され たガスを凝縮（液化）させることで，バブル欠陥を抑止す る。PFPは室温の飽和蒸気圧が $0.15 \mathrm{MPa}$ であり, 大気圧 $(0.1 \mathrm{MPa})$ で捕獲された PFP はインプリントプロセス中のわ ずかな加圧により液化する。液化により PFP ガスの体積は $1 / 200$ に減少するだけでなく, 光硬化樹脂への溶解や光硬 化樹脂とモールドとの界面に広がることでバブルの発生を 抑止し, 図 2(b) のような樹脂の完全充填が可能になる ${ }^{13)}$ 。

\section{4 残膜厚の均一化手法}

ナノインプリントリソグラフィにより形成した樹脂パ ターンの下層の材料を加工する場合には，まず樹脂パター ンの溝底部にある残膜を除去することが必要である。残膜 除去プロセスでは成型したパターンへの影響を極力小さく したいため残膜は薄く均一であることが望ましい。残膜厚 は使用する樹脂量とパターン形成に使用する樹脂量（モー ルドの凹部。容積）の差によりほぼ決定されるため，残膜 厚を薄くするためにはこれらの量をほぼ一致させる必要が ある。回路パターンなどのレイアウトで粗密がある場合 は，一般的なスピンコートによる均一の膜厚の樹脂膜では 全域で樹脂の供給量と使用量を一致させることができず, 通常のモールド（図 3(a)）を使用すると残膜厚が場所によ り異なり（図 3(b)), 残膜除去プロセスやその後の下層基板 へのプロセスに問題が発生する。半導体製造用のナノイン プリント装置ではこの問題に対応するために, インク (a)
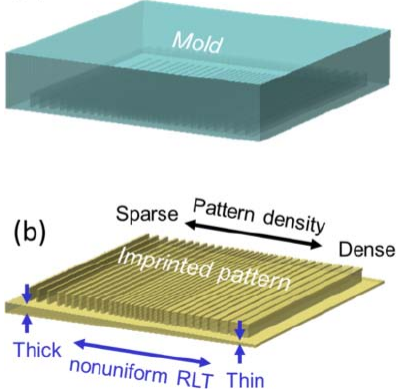

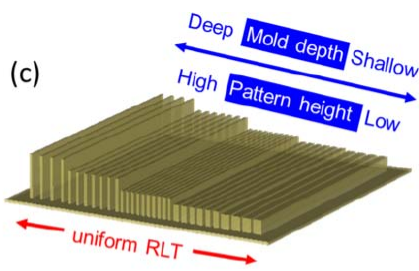

(d)

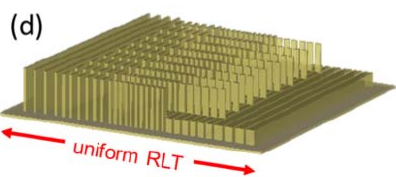

図 3. パターン密度起因の残膜厚変化を補正する容積均一 化手法（モールド側の深さ変化を図示するのが難し いためインプリントパターン側で表現） (a) 通常の モールド，(b) 通常のモールドでのインプリント結 果, (c) 容積均一化の基本的な考え方, (d) 2 段階の 深さによる容積均一化 
ジェット方式にて $1 \mathrm{pL}$ 程度の液滴状の樹脂をパターンの粗 密に合わせて供給する手法が害用化されている。液滴の配 置を工夫することで樹脂の供給量と使用量を一致させ，ま た，液滴どうしが上手く連結し，モールドに高速に樹脂が 充填されるような工夫がされている。この手法は, パター ンの粗密に対応した樹脂の供給側の工夫であるが, 樹脂の 使用側での工夫によりスピンコート膜を利用可能にする手 法も提案されている。パターンの疎の部分では樹脂の使用 量が少ないのが問題であるので, モールドの疎の部分のパ ターンの媣さを密の部分のパターンの深さより媣くして, いずれの場所でも樹脂の消費量が等しくなるようにするこ とで対応する。単純には, 複数のパ夕ーン密度に対し, 複 数のパターンの媣さを用意すれば良いとなるが（図 3(c)),

段数の多い多段モールドはプロセスが複雑になるため 2 段 の深さで多段と同等の効果を有するモールド (図 3(d)) とそ の作製手法が提案されている。このモールドはパターン密 度にかかわらず容積が一定になっており, 容積均一化モー ルドと呼ばれる。パターンに粗密がある場合に発生する残 膜の不均一性は容積均一化により改善されることが実証さ れている (図 4) ${ }^{17)}$ 。容積均一化では, モールドのパターン

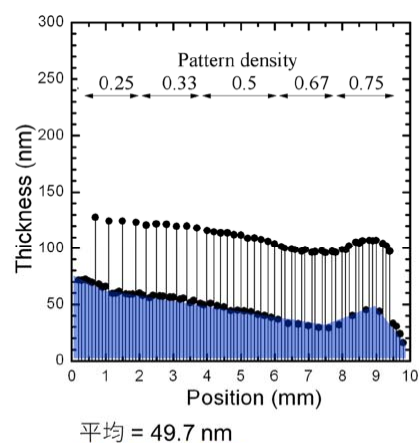

標準偏差 $=13.6 \mathrm{~nm}$

(a) 通常のモールド

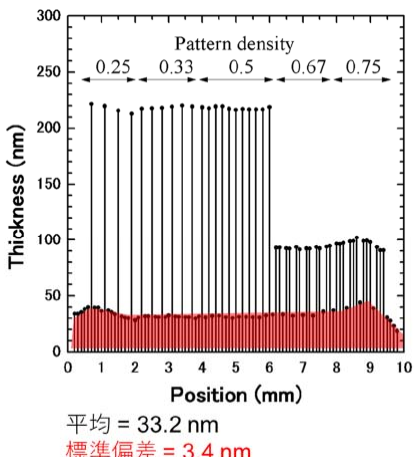

標準偏差 $=3.4 \mathrm{~nm}$
図 4. 通常のモールドと容積均一化モールドでの残膜厚の 比較 ${ }^{17)}$
を部分的に深堀するために，1段目のエッチングで使用す るハードマスクをエッチングプロセス後も除去せずに 2 段 目のエッチングでも使用するセルフアライメントプロセス とすることで 1 段目に整合して 2 段目のエッチングが可能 である。溝の深さが異なるためにモールド側でパターンの 浅い部分と梁い部分や，その部分で形成したナノインプリ ントパターン，最終的にはそれを利用して下層の基板を加 工した結果での線幅の違いが気になるところであるが，プ ロセスの改良によりほほ違いが識別できないレベルに加工 ができることが確かめられている(図 5) ${ }^{18)}$ 。また，このよ うな 2 段目のエッチングのために必要となるマスクパター ンを元のパターンデータから自動生成する STAMP (Stamp Topography Automated Modification Program) と呼ばれるプロ グラムも開発されている ${ }^{19) 。 ~}$

\section{5 ナノインプリントパターンの歪補正}

ナノインプリントパターンはモールドの反転形状である ため，非常に高い再現性でほぼ同一のパターンを形成でき る。一方, 光リソグラフィでは, 倍率などを変化させるこ とができるため, パターンレイアウトを微調整することも 可能である。重社合わせ露光を考えた場合，光リソグラ フィでは形成済みのパターンを基準に倍率などを調整し,

精度よく重称合わせが行えるのに対し，ナノインプリント では通常はそのようなことが行えない。この問題に対応す るために，モールドを周囲から押すことでインプリントに おいても微小ながらも倍率を変化させる手法が提案されて いる ${ }^{20)}$ 。この手法では，モールドを縮小する方向の補正の みが可能であるため，モールドには設計よりもやや大きめ のパターンを作製することで，縮小だけでなく拡大方向の 補正も行える様になっている。この手法では，モールドを 線形に変化させるため 1 次の補正のみが行える。半導体作 製などでは重㸚わせ精度への要求が高く，また， 1 次の 補正では対応できないような場合の補正も要求されてい る。近年，これらへの対応のためにウエハの光加熱による 膨張を利用した高次の補正方法が提案され実用化されてい

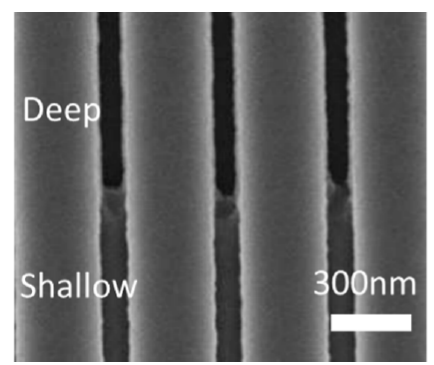

(a ）モールド

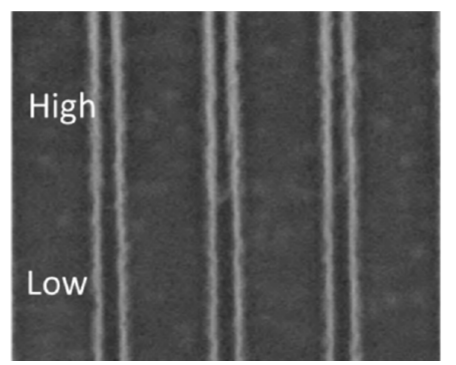

（b）インプリントパターン

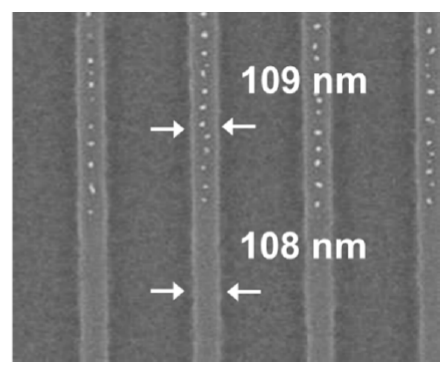

（c）Si 基板加工後

図 5. 容積均一化モールドによるナノインプリントと Si 基板加エ ${ }^{18)} \quad$ ((c) は Si 基板加工のため のドライエッチング後にインプリント樹脂除去のためのアッシングを行っている。線上に 並ぶドットはアッシング不足による残椬であり，インプリントパターンの高低による最終 線幅への影響はほとんどないことが分かる。） 


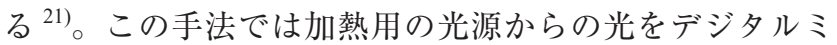
ラーデバイスにより意図した光強度分布を持たせて, 光硬 化のための光路に合流させてモールドを透過させシリコン 基板を照射する。シリコン基板は所望の光強度分布で加熱 され適当な時間でシリコン基板に意図した変形を起こさせ る。そのタイミングで硬化のための光照射を行うことで 2 次以上の重ね合わせ補正が実現される。

\section{6 ナノインプリントパターンの線幅制御}

凝縮性ガス PFP は優れたバブル抑止効果があり, $45 \mathrm{~nm}$ 程度のラインアンドスペースパターンへの作製に適用可能 であることが示されている (図 6 $)^{22)}$ 。また, 副次効果とし て, 離型性の向上や, 樹脂の低粘度化によるスループット の向上などの効果もある。一方で, PFPの利用は樹脂に よっては収縮率を大きくし, また, ラインエッジラフネス や表面粗さの増大などの副作用がある場合もある。望まし くない副作用を防ぐために，樹脂側の改良指針が明らかに

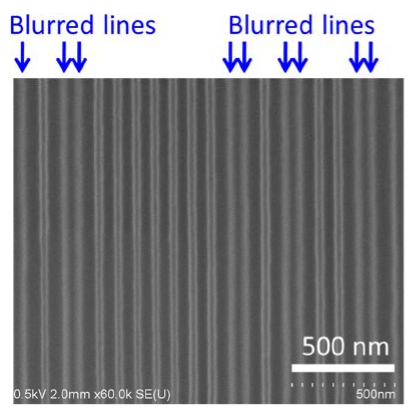

(a) 大気中プロセス
All lines are sharply defined.

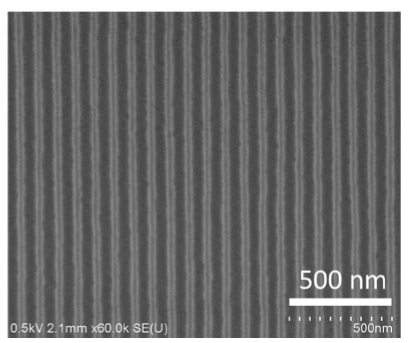

(b) PFP 中プロセス
図 6. $45 \mathrm{~nm}$ ラインアンドスペースのナノインプリントパ ターン 22)
なっている他に, PFP 以外の凝縮性ガスを利用する手法も 試みられている。現在, PFPはわれわれの光ナノインプリ ントに必須となっているが, PFP は地球温暖化係数が 1030 であり，将来的な工業利用を考えると，同様の効果を発揮 し, より小さい地球温暖化係数を有するガスを見出して おく必要がある。表 1 に示す CTFP (trans-1-Chloro-3,3,3Trifluoropropene) $)^{23)}$ と TFP (trans-1,3,3,3-Tetrafluoropropene) ${ }^{24)}$ はその有力な候補と考えている。これらの地球温暖化係数 はPFP の $1 / 100$ 以下であり, 室温での飽和蒸気圧はそれぞ れ $0.13 \mathrm{MPa}$ と $0.5 \mathrm{MPa}$ である。CTFP の特性は PFP とよく 似て PFP を代替できると推測され，実験的にも利用できる ことが確かめられた。ただし，CTFP 中プロセスは PFP 中 プロセスに対し，パターンの収縮率は同程度で, 表面粗さ がやや大きかった。TFP は PFP に対して高い飽和蒸気圧を 有するために凝縮させるためには, 一見, 高いインプリン 卜印加圧力が必要と考えられるが, 実は, パターン線幅や 残膜厚が小さくなると溝内や残膜内で形成されるバブルも 小さくなるためにバブルと光硬化樹脂界面でのラプラス圧

表 1.PFP の代替ガスの候補 CTFP と TFP の特性

\begin{tabular}{l|c|c}
\hline & $\begin{array}{c}\text { Trans -1-Chloro-3,3,3- } \\
\text { trifluoropropene }(\mathrm{CTFP})\end{array}$ & $\begin{array}{c}\text { trans-1,3,3,3- } \\
\text { tetrafluoropropene (TFP) }\end{array}$ \\
\hline Molecular formula & $(\mathrm{E}) \mathrm{CF}_{3}-\mathrm{CH}=\mathrm{CClH}$ & trans- $\mathrm{CF}_{3} \mathrm{CH}=\mathrm{CHF}$ \\
\hline Molecular weight & 130 & 114 \\
\hline Boiling point $\left[{ }^{\circ} \mathrm{C}\right]$ & 19 & -19 \\
\hline $\begin{array}{l}\text { Saturated vapor pressure } \\
\text { at } 25^{\circ} \mathrm{C}[\mathrm{MPa}]\end{array}$ & 0.129 & 0.5 \\
\hline $\begin{array}{l}\text { Ozone depletion potential } \\
(\mathrm{ODP})\end{array}$ & 0 & 0 \\
\hline $\begin{array}{l}\text { Global warming potential } \\
(\mathrm{GWP})\end{array}$ & $1 \sim 5$ & 6 \\
\hline
\end{tabular}

(a)

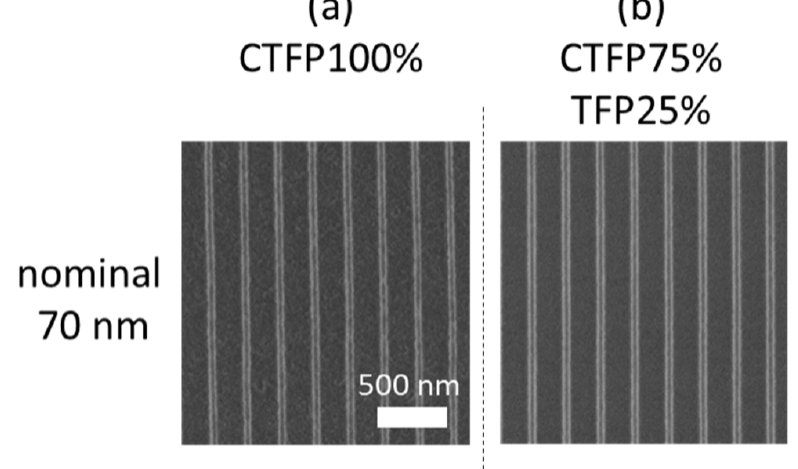

(c) CTFP50\% TFP50\% (d) CTFP25\%

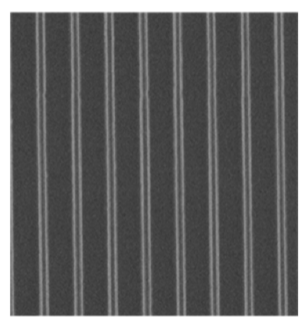
TFP75\%

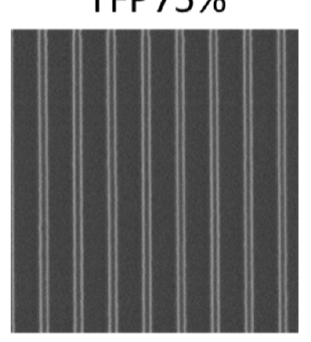

(e)

TFP100\%
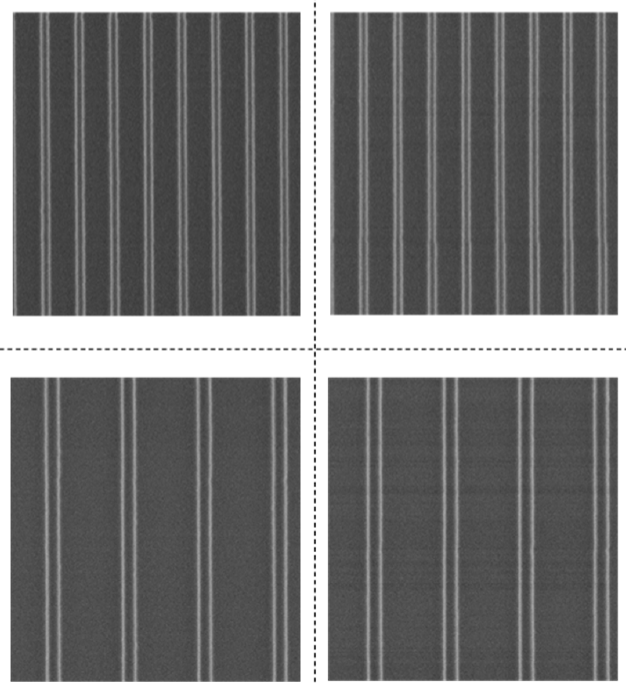

図 7. CTFP と TFP の混合ガスを利用したナノリンプリントパターンの線幅制御 ${ }^{25)}$ 
が大きくなる。これが TFP の飽和蒸気圧を上回るために小 さなインプリント印加圧力でもバブル欠陥を抑止すること が可能になる。このことは, 実験によっても確かめられて いる。TFP 中のプロセスで形成されたパターンは大気中や $\mathrm{He}$ 中プロセスと同等のラインエッジラフネスを示し ${ }^{24)}$, 数十 $\mathrm{nm}$ 以下のパターン形成では非常に有用である。また, PFP が樹脂の収縮率を増大させるのに対して，TFP はあま り増大させないことが分かった。さらに，樹脂の収縮率が CTFP と TFP で異なることを利用し，それらの混合ガスの 比率を変えることでパターン幅の微調整が可能である（図 7) ${ }^{25)}$ 。これは, 光リソグラフィでの露光量を変化させた場 合に相当する。

\section{4. おわりに}

ナノインプリントは提案されてから 20 年以上が経過し, 多くの課題を克服し進化を遂げ, 半導体製造に適用される レベルまでに成熟しつつある。技術の進展により, 当初, 不可能と考えられていた, 倍率補正, 高次歪補正, 線幅制 御なども可能となっている。ステップアンドリピート方式 のナノインプリントが半導体製造で実用化しつつあるのに 対し, ナノ構造を大面積に一度に形成するウエハ一括方式 のナノインプリントは有望視されながらも限定的な利用に とどまっている。これは, 大面積にナノパターンを低コス トで作製することに制限があったからである。現在，大面 積モールド作製用の低コスト超高速電子ビーム描画装置が 開発されつつあり（プロジェクト名「ウェハーサイズ 3 次 元ナノインプリントモールド用超高速電子ビーム加工装置 の研究開発」), ウエハ一括方式に対応できる低コストの モールド作製が行えるようになることで, 今後, 半導体以 外の分野に扔いてもナノインプリントリソグラフイが進展 することを期待している。

(2018.12.21- 受理)

\section{文献}

1) S. Y. Chou, P. R. Krauss, and P. J. Renstrom: "Imprint of sub-25 $\mathrm{nm}$ vias and trenches in polymers," Appl. Phys. Lett., Vol. 67, No. September, p. 3114, 1995

2) J. Haisma, M. Verheijen, K. van den Heuvel, and J. van den Berg: "Mold-assisted nanolithography: A process for reliable pattern replication,” J. Vac. Sci. Technol. B, Vol. 14, No. 6, pp. 41244128, 1996

3) M. Colburn, S. C. Johnson, M. D. Stewart, S. Damle, T. C. Bailey, B. Choi, M. Wedlake, T. B. Michaelson, S. V. Sreenivasan, J. G. Ekerdt, and C. G. Willson: "Step and flash imprint lithography: a new approach to high-resolution patterning," Emerging Lithographic Technologies III (Vol. 3676, pp. 379-390). International Society for Optics and Photonics, 1999

4) N. Khusnatdinov, Z. Ye, K. Luo, T. Stachowiak, X. Lu, J. W. Irving,
M. Shafran, W. Longsine, M. Traub, V. Truskett, B. Fletcher, W. Liu, F. Xu, D. LaBrake, S. V. Sreenivasan, and D. J. Resnick: "High-throughput jet and flash imprint lithography for advanced semiconductor memory," Alternative Lithographic Technologies VI (Vol. 9049, p. 904910). International Society for Optics and Photonics, 2014

5) S. Y. Chou, P. R. Krauss, and P. J. Renstrom: "Nanoimprint lithography,” J. Vac. Sci. Technol. B, Vol. 14, No. 6, pp. 4129 4133, 1996

6) S. Y. Chou, P. R. Krauss, W. Zhang, L. Guo, and L. Zhuang: "Sub$10 \mathrm{~nm}$ imprint lithography and applications," J. Vac. Sci. Technol. B, Vol. 15, No. 6, pp. 2897-2904, Nov. 1997

7) G. Tan, N. Inoue, T. Funabasama, M. Mita, N. Okuda, J. Mori, K. Koyama, S. Kaneko, M. Nakagawa, A. Matsuda, and M. Yoshimoto: "Formation of 0.3-nm-high stepped polymer surface by thermal nanoimprinting," Applied Physics Express, Vol. 7, No. 5, p. 055202, 2014

8) M. D. Austin, W. Zhang, H. Ge, D. Wasserman, S. A. Lyon, and S. Y. Chou: "6 nm Half-pitch lines and $0.04 \mu \mathrm{m} 2$ static random access memory patterns by nanoimprint lithography," Nanotechnology Vol. 16, p. 1058, 2005

9) F. Hua, A. Gaur, Y. Sun, M. Word, N. Jin, I. Adesida, M. Shim, A. Shim, and J. A. Rogers: "Processing Dependent Behavior of Soft Imprint Lithography on the 1-10-nm Scale," IEEE Transactions on Nanotechnology, Vol. 5, No. 3, pp. 301-308, 2006

10) Y. Kurashima, I. Miyamoto, H. Hiroshima, and T. Itatani: "Evaluation of UV-nanoimprinted surface roughness using Si mold with atomically flat terraces,” Jpn. J. Appl. Phys., Vol. 46, No. 41-44, pp. 1083-1085, 2007

11) T. Bailey, B. J. Choi, M. Colburn, M. Meissl, S. Shaya, J. G. Ekerdt, S. V. Sreenivasan, and C. G. Willson: "Step and flash imprint lithography: Template surface treatment and defect analysis," J. Vac. Sci. Technol. B, Vol. 18, No. 6, pp. 3572-3577, 2000

12) S. Matsui, H. Hiroshima, Y. Hirai, and M. Nakagawa: “Innovative UV nanoimprint lithography using a condensable alternative chlorofluorocarbon atmosphere," Microelectron. Eng., Vol. 133, pp. $134-155,2015$

13) H. Hiroshima and M. Komuro: "Control of bubble defects in UV nanoimprint,” Jpn. J. Appl. Phys., Vol. 46, No. 9 B, pp. 63916394, 2007

14) H. Hiroshima, M. Komuro, N. Kasahara, Y. Kurashima, and J. Taniguchi: "Elimination of pattern defects of nanoimprint under atmospheric conditions,” Jpn. J. Appl. Phys., Vol. 42, No. 6 B, pp. 3849-3853, 2003

15) M. Hanabata, S. Takei, S. Nakajima, N. Sugino, Y. Matsumoto, and A. Sekiguchi: "Nanoimprint lithography using gas permeable 
template," Advances in Patterning Materials and Processes XXXIV (Vol. 10146, p. 101461I), International Society for Optics and Photonics, 2017

16) K. Usuki: "Resist Materials for UV Nanoimprint Lithography: Approaches to Rapid Resist Spreading on Dispensing Based UV-NIL,” J. Photopolym. Sci. Technol., Vol. 29, No. 1, pp. $45-51,2016$

17) H. Hiroshima: "Nanoimprint with thin and uniform residual layer for various pattern densities," Microelectron. Eng., Vol. 86, No. 4-6, pp. 611-614, 2009

18) K. Suzuki, S. W. Youn, Q. Wang, H. Hiroshima, and Y. Nishioka: "Uniform residual layer creation in ultraviolet nanoimprint using spin coat films for sub-100-nm patterns with various pattern densities,” Jpn. J. Appl. Phys., Vol. 52, No. 6S, 06GJ06, 2013

19) S.-W. Youn, K. Suzuki, and H. Hiroshima: "Chip-scale pattern modification method for equalizing residual layer thickness in nanoimprint lithography,” Jpn. J. Appl. Phys., Vol. 57, No. 6S1, p. 06HG03, 2018

20) J. Choi, K. Nordquist, A. Cherala, L. Casoose, K. Gehoski, W. J. Dauksher, S. V. Sreevivasan, and D. J. Resnick: “Distortion and overlay performance of UV step and repeat imprint lithography," Microelectronic Engineering, Vol. 78, pp. 633-640

21) M. Hiura, T. Hayashi, A. Kimura, and Y. Suzaki: "Overlay improvements using a novel high-order distortion correction system for NIL high-volume manufacturing," Emerging Patterning Technologies (Vol. 10584, p. 105840U). International Society for
Optics and Photonics, 2018

22) H. Hiroshima, Q. Wang, and S. W. Youn: " $45 \mathrm{~nm}$ hp line/space patterning into a thin spin coat film by UV nanoimprint based on condensation,” J. Vac. Sci. Technol. B, Vol. 28, No. 6, pp. C6M12-C6M16, 2010

23) K. Suzuki, S. W. Youn, and H. Hiroshima: "Bubble-free high-speed UV nanoimprint lithography using condensable gas with very low global warming potential,” Jpn. J. Appl. Phys., Vol. 55, No. 7, pp. 076502-1-076502-5, 2016

24) K. Suzuki, S. W. Youn, and H. Hiroshima: "Bubble-free patterning with low line edge roughness by ultraviolet nanoimprinting using trans-1,3,3,3-tetrafluoropropene condensable gas," Appl. Phys. Lett., Vol. 109, No. 14, pp. 1-2, 2016

25) K. Suzuki, S. W. Youn, and H. Hiroshima: "Ultraviolet nanoimprint lithography in the mixture of condensable gases with different vapor pressures," J. Photopolym. Sci. Technol., Vol. 29, No. 2, pp. $181-187,2016$

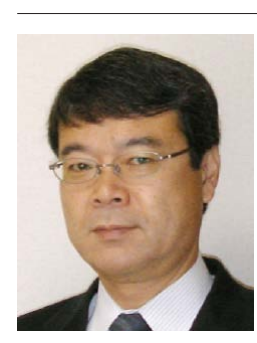

廣島 洋（ひろしまひろし）

著者紹介

国立研究開発法人 産業技術総合研究所 集積マ イクロシステム研究センター 研究センター長 電子ビームリソグラフィ, 光ナノインプリントリ ソグラフィの研究開発に従事 